\title{
RECICLAGEM DE PAPEL E O DESENVOLVIMENTO DE AÇÕES SUSTENTÁVEIS: UMA PARCERIA ENTRE O Pibid INTERDICISPLINAR EM EDUCAÇÃO AMBIENTAL E A Com-Vida ESCOLAR
}

\author{
Cauane Rocha Santos ${ }^{1}$ \\ Talita Costa Santana ${ }^{2}$ \\ Rosemary Brito dos Reis Azevedo ${ }^{3}$ \\ Patrícia Souza Leal Pinheiro 4 \\ Silvana do Nascimento Silva ${ }^{5}$
}

Resumo: A Oficina de reciclagem de papel, com a intervenção do Pibid Interdisciplinar em Educação Ambiental/UESB, campus de Jequié-BA, com os integrantes da Comissão de Meio Ambiente e Qualidade de Vida (Com -Vida), em uma das escolas parceiras, evidencia a importância da Educação Ambiental (EA) para se enfrentar a crise civilizatória instalada em nosso país no que se refere aos problemas socioambientais. $O$ objetivo final era enfatizar a prática de reciclagem do papel como ação sustentável, visando reduzir a quantidade deste resíduo jogado no lixo da escola. Concluímos que EA pode contribuir para a sustentabilidade através do fazer pedagógico, construindo conhecimentos e valores na formação de cidadãos críticos e reflexivos.

Palavras-chave: Educação Ambiental; Pibid; Reciclagem de papel; Sustentabilidade

${ }^{1}$ Universidade Estadual do Sudoeste da Bahia - UESB. Licencianda em Ciências Biológicas. Ex-Bolsistas de Iniciação à Docência do Pibid-Interdisciplinar Educação Ambiental. E-mail: cauaner.s@gmail.com.

2 Universidade Estadual do Sudoeste da Bahia - UESB. Licencianda em Ciências Biológicas. Ex- Bolsistas de Iniciação à Docência do Pibid-Interdisciplinar Educação Ambiental. E-mail: talitaaum@gmail.com.

${ }^{3}$ Professora da Educação Básica. Ex-Professora Supervisora do Pibid-Interdisciplinar Educação Ambiental. Email: rosemarynte6@hotmail.com.

${ }^{4}$ Universidade Federal da Bahia -UFBA. Doutoranda pelo Doutorado Multi-Institucional e Multidisciplinar em Difusão do Conhecimento. Professora da Educação Básica. Grupo de Pesquisa em Educação Ambiental e Formação de Professores. E-mail: patylealpinheiro@hotmail.com.

5 Universidade Estadual do Sudoeste da Bahia - UESB. Ex-Coordenadora do Pibid-Interdisciplinar Educação Ambiental. Coordenadora do Grupo de Pesquisa Educação Ambiental e Formação de Professores. Departamento de Ciências Biológicas. E-mail: siluesb@hotmail.com 


\section{Introdução}

A Educação Ambiental é primordial para o desenvolvimento de cidadãos, na medida em que, como espaço formador, a escola, ao possibilitar discussões sobre questões ambientais e incentivar proposições pedagógicas em busca de ações sustentáveis, procura compor formas de atuação em busca de melhoria da qualidade de vida.

Em consonância com Loureiro (2004, p.16), "[a] educação não é o único, mas certamente é um dos meios de atuação pelos quais nos realizamos como seres em sociedade", ressaltando que nas novas experiências de ações sustentáveis, são construídos conhecimentos para refletir criticamente a relação do homem com o mundo e ele passa a se sentir como parte dele. Este confronto entre teoria e prática, estabelecendo uma relação entre eu e o outro, possibilita a transformação individual pela ação coletiva, cotidiana e comunitária, permitindo construir o sentido de pertencimento à sociedade.

O lixo causa vários problemas a todos, uma vez que é resultado do modelo de desenvolvimento do mundo atual, vinculado ao incentivo do consumo desenfreado. Isso gera acumulação de dejetos que, na maioria das vezes, não recebem um destino e tratamento adequados, aumentando os impactos ambientais negativos. Dessa forma, o papel, um dos produtos mais utilizados nas tarefas do cotidiano, pode produzir quantidade considerável de resíduos que são descartados inadequadamente. Assim, os problemas ambientais gerados pelo papel decorrem não apenas de sua produção, mas também, do corte de árvores (ocasionando o desmatamento) e do processo industrial (provocando a poluição), além dos gastos de água e energia.

Por outro lado, a reciclagem do papel usado e descartado garante seu reaproveitamento. Como ele é produzido a partir da celulose de determinados tipos de árvores, como eucalipto e pinus, quando se reutiliza papel reciclado, contribui-se para a preservação do meio ambiente, pois árvores deixarão de ser cortadas. Porém, além dessa importância ecológica, há também a importância econômica, pois a reciclagem gera muita renda para milhares de pessoas que atuam, principalmente, em cooperativas.

Essas constatações fundamentam a decisão do Programa Institucional de Bolsa de Iniciação à Docência (Pibid) - Subprojeto Interdisciplinar em Educação Ambiental que, juntamente com os integrantes da Comissão de Meio Ambiente e Qualidade de Vida na Escola (Com-Vida), propiciou a realização de uma oficina tendo como objetivo adotar prática de reciclagem do papel como ação sustentável e reduzir a quantidade de papel que vai para o lixo da escola parceira do projeto. 


\section{Fundamentação teórica}

\section{Pibid e Com-Vida}

O Pibid é um programa institucional vinculado à Coordenação de Aperfeiçoamento de Pessoal de Nível Superior (Capes) que objetiva inserir os discentes em formação inicial no chão da escola, de forma a estabelecer uma interação entre universidade e escola. Nesse sentido professores universitários, professores da escola básica e licenciandos interagem em busca do desenvolvimento de uma práxis pedagógica voltada para os anseios e inquietações que perpassam no contexto escolar e na formação docente.

Silva e Carvalho $(2015$, p.9) especificam assim, com muita clareza, os objetivos do Pibid:

Partindo deste princípio, o Programa Institucional de Bolsas de Iniciação a Docência (Pibid), em convênio com a Coordenação de Aperfeiçoamento de Pessoal de Nível Superior (Capes), objetiva aproximar os licenciandos dos cursos de graduação das Instituições de Ensino Superior à realidade das escolas de rede publica de ensino. Além de promover a formação do professor-pesquisador a partir do desenvolvimento de ações colaborativas entre universidades e escolas parceiras. Sendo assim, o Pibid-Microrrede Ensino-Aprendizagem-Formação com o subprojeto Interdisciplinar-linha de ação em EA foi elaborado para promover a problematização crítica dos problemas ambientais, em que atores sociais (licenciados, professores da unidade de ensino, professores universitários e comunidade escolar) discutam, dialoguem e desenvolvam valores, conhecimentos, habilidades, competências, procedimentos, ações e atitudes em prol da sociedade sustentável.

Especificamente no âmbito do Pibid Subprojeto Interdisciplinar Educação Ambiental, a interação entre os atores sociais envolvidos, no caso, os bolsistas ID, supervisoras e coordenadoras no período de março de 2014 - junho de 2016, se desenvolveu a partir de ações planejadas de forma colaborativa nas reuniões semanais do grupo na Universidade Estadual do Sudoeste da Bahia, e realizadas pelos bolsistas ID na escola parceira.

$\mathrm{Na}$ escola parceira, os bolsistas ID conseguiram reativar a Com -Vida e, juntamente com os membros desta comissão, realizaram inúmeras ações em consonância com o que preconiza cada coletivo.

O principal papel da Com-Vida é contribuir para um dia-a-dia participativo, democrático, animado e saudável na escola, promovendo o intercâmbio entre a escola e a comunidade. Por isso, a Com-Vida chega para somar esforços com outras organizações da escola, como o Grêmio Estudantil, a Associação de Pais e Mestres e o Conselho da Escola, trazendo a Educação Ambiental para todas as disciplinas (BRASIL, 2004, p.9)

Revbea, São Paulo, V. 12, № 2: 114-126, 2017. 
O Pibid Educação Ambiental e a Com-Vida passam a constituir um coletivo que se preocupa com a problematização das questões socioambientais, visando a promover a formação do sujeito socioambientalmente responsável (SILVA; EL-HANI, 2014) e, para isso, o envolvimento de outras organizações da escola é de extrema importância para a realização das ações problematizadoras.

Nesse sentido, trabalhar com a Educação Ambiental passa a ser uma meta vinculada aos princípios da sustentabilidade, em que discutir a produção e o consumo dos bens materiais é de extrema importância para entender 0 papel da reciclagem no contexto escolar.

\title{
Educação Ambiental para a sustentabilidade
}

A Política Nacional de Educação Ambiental foi estabelecida através da lei $n^{\circ}$ 9.795, de 27 de abril de 1999, entendida como "componente essencial e permanente da educação nacional", devendo estar presente em caráter formal e não formal, sendo um direito de todos (artigo $2^{\circ}$ e $3^{\circ}$ ) (BRASIL, 1999). É preciso observar que a escola deve se embasar na lei, incluindo a Educação Ambiental como direito de todos os alunos. E, de acordo com essa lei, deve-se entender por Educação Ambiental:

\begin{abstract}
[...] os processos por meio dos quais o indivíduo e a coletividade constroem valores sociais, conhecimentos, habilidades, atitudes e competências voltadas para a conservação do meio ambiente, bem de uso comum do povo, essencial à sadia qualidade de vida e sua sustentabilidade (BRASIL,1999, p.1).
\end{abstract}

Levando em consideração o que preconiza a lei vista anteriormente e refletindo que a escola tem a função precípua na transmissão dos conhecimentos e formação do indivíduo para ser atuantes e participativos na sociedade, cabe indagar se a escola atual prepara os alunos para refletirem sobre o individual e o coletivo, se possibilita a construção de valores sociais, conhecimentos, atitudes e competências voltadas para a conservação do meio ambiente, qualidade de vida e sustentabilidade.

Vale, portanto, supor que o papel da escola seria o de oferecer oportunidades para se analisarem os problemas ambientais e globais e para que os alunos aprendam a interagir e intervir no mundo, superando o individualismo e considerando possíveis soluções. Mas o que se observa é que a visão instrumentalizada da natureza, muitas vezes transmitida nas aulas, condiciona o comportamento dos alunos de tal forma que as relações entre seres humanos e o meio ambiente são padronizadas conforme a lógica 'sujeito - objeto' (PINHEIRO, 2015, p.25).

Assim, a crise ambiental se caracteriza como sendo a expressão da crise civilizatória, que hoje é decorrente de um processo histórico que colocou 
a sociedade humana e a natureza de lados opostos. Nesse contexto, os seres humanos se sentem cada vez mais como partes isoladas, estabelecendo-se uma relação de dominação da natureza em que prevalecem os interesses individuais e/ou coletivos das necessidades biológicas e socioeconômicas (GUIMARÃES, 2007). Dessa forma, o antropocentrismo domina as relações homens - natureza, pois os seres humanos se colocam num patamar superior àquele dos demais seres vivos. "Assim é preciso revolucionar o processo educativo, deixando as velhas fórmulas de ensinar ciências, criando mais espaço para a Educação Ambiental" (PINHEIRO, 2015, p.26).

Contudo, é lícito acreditar que a educação possa transformar essa realidade. No entender de Jacob (2004), a educação, como meio de mediar a informação, representa a possibilidade de motivar as pessoas para a mudança de atitude e para uma participação social que defendam a qualidade de vida. Sendo assim, a Educação Ambiental assume um papel fundamental na transformação de indivíduos responsáveis que promovam o desenvolvimento sustentável. Então, a Educação Ambiental defendida por Loureiro (2007) é bastante complexa e estabelece relações de movimento no tempo e espaço, vai além do ensino de conteúdos biológicos, destacadamente os de cunho ecológico, os temas relacionados à prevenção ou ao respeito à natureza são problematizados nas dimensões culturais, econômicas, políticas, históricas e sociais.

Nesse sentido, a escola deve ser um espaço de geração de novos atores sociais que compreendam a complexidade ambiental e, para conseguir isso, ela deve oferecer um processo educativo articulado, que privilegia o diálogo entre diferentes áreas do saber e compromissado com a sustentabilidade (JACOB, 2004). Portanto, a escola deve proporcionar um ensino aprendizagem de forma que os atores sociais resignifiquem o saber e 0 compromisso com o meio ambiente e a sustentabilidade.

\section{Origem do papel e suas finalidades}

A celulose é uma fibra encontrada em todas as plantas e serve como matéria-prima para a fabricação de papel. No Brasil, é obtida a partir das árvores de pinus, que possuem fibras longas e mais resistentes, próprias para embalagens. Nota-se que, no eucalipto, as celuloses são mais curtas, servindo para a produção de papéis de escrever, papel higiênico, guardanapos, etc. As empresas de celulose no Brasil ganham destaque em relação às dos outros países porque, no processo, as árvores são cultivadas e, depois de sua retirada para o processo industrial, o terreno recebe novo plantio florestal (BRACELPA, 2009).

Existe um decreto de fevereiro de 2010, que determina o uso de papel certificado nos livros que são distribuídos aos alunos da rede pública pelo Programa Nacional do Livro Didático (PNLD) do Ministério da Educação. Esse decreto tem como principais pontos a proteção da natureza e o reconhecimento dos processos sustentáveis da indústria, pois, para que o papel seja certificado 
é preciso que nenhuma árvore seja cortada ilegalmente, que a empresa garanta direitos trabalhistas e não traga prejuízos para comunidades das áreas florestais (BRACELPA, 2010).

\section{Reciclagem de resíduos sólidos}

É muito comum que em todo lugar onde haja atividade humana ocorra a produção de resíduos sólidos, porém, não é aceitável que a sociedade ignore todo esse material produzido, que o descarte sem a preocupação de tratá-lo, prejudicando e causando a poluição do ambiente. Os resíduos sólidos são a principal realidade dos centros urbanos, havendo aumento na quantidade e na diversidade, tornando-se algo inerente do ser humano, resultante principalmente do modo de vida atual da sociedade que está sempre em busca de suprir suas necessidades e assegurar seu conforto (SÃO PAULO, 2011).

Nos últimos tempos, os seres humanos passaram a produzir e consumir com frequência de modo desvinculado de suas necessidades, mas pelo simples fato de 'ter', 'querer' e 'poder'. Trajber (2007) explica isso quando afirma que:

Muitos dos grandes problemas ambientais que enfrentamos podem ser relacionados, direta ou indiretamente, com a apropriação e uso de bens, produtos e serviços, suportes da vida e das atividades de uma sociedade historicamente construída sobre uma perversa lógica de mercado (TRAJBER, 2007, p. 144).

Com isso, a sociedade acaba consumindo além do que precisa e o destino de tudo isso é o lixo que, na maioria das vezes, é descartado inadequadamente, causando diversos problemas ambientais. Em relação ao papel, ele está presente em quase tudo: embalagens, livros, revistas, jornais, cadernos escolares, cédulas de dinheiro, guardanapos entre muitos outros produtos. Isto determina um consumo exagerado, a que corresponde um exagerado volume de lixo, sem que se preste a devida atenção quanto a seu destino. Segundo Alencar (2005),

[...] a reciclagem é o resultado de uma série de atividades pelas quais os materiais que se tornariam lixo ou que estão no lixo sejam desviados, coletados, separados e processados para serem usados como matéria-prima na manufatura de novos produtos (p. 101).

Portanto, a reciclagem de papel usado, além de reduzir a grande quantidade de resíduos jogados em áreas urbanas, diminui a extração de recursos naturais trazendo benefício para o meio socioambiental e para a economia de um país, gerando emprego e renda familiar. 


\section{Metodologia}

A oficina de reciclagem de papel foi dividida em quatro encontros com os integrantes da Com-Vida. No primeiro encontro, foi lido um texto explicando a importância de se reciclar o papel e o método de reciclagem a ser empregado. Houve, em seguida, a exibição de um vídeo, mostrando o passo a passo da reciclagem.

O segundo encontro foi um teste, que consistiu da execução de todo o processo de reciclagem do papel, antes de aplicar a prática com os participantes. O terceiro e quarto encontros foram realizados no laboratório de ciências juntamente com os integrantes da Com-Vida. $O$ processo de reciclagem foi então executado integralmente, utilizando-se para a reciclagem um papel usado na secretaria da própria escola e que seria destinado ao lixo.

a) O caminho percorrido na realização do processo está descrito e explicado nos tópicos a seguir: o papel a reciclar foi picado em pequenos pedaços que ficaram de molho durante 24 horas em uma bacia (Figura 1):

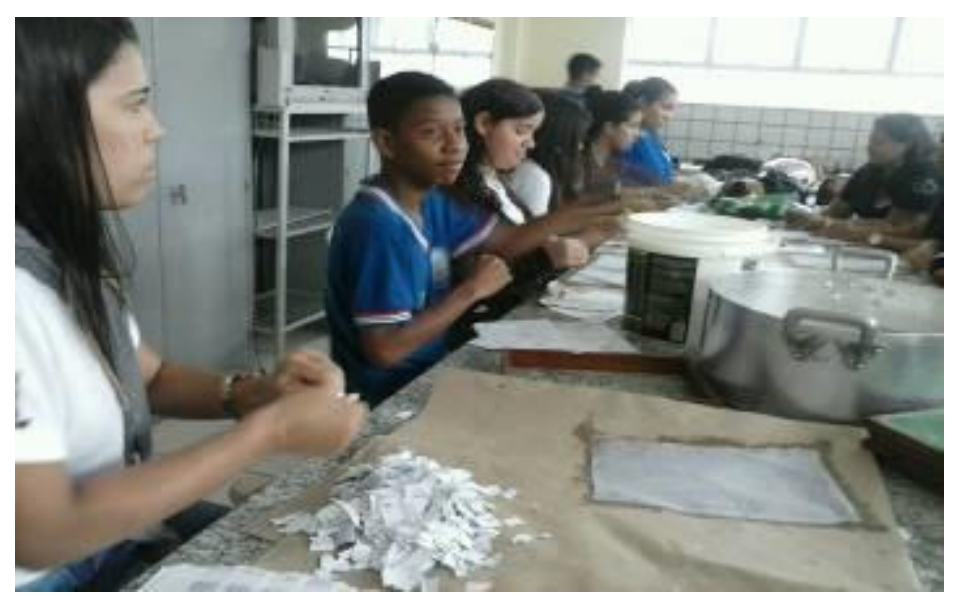

Figura 1: Bolsistas do Pibid e integrantes da Com-Vida, no Laboratório de Ciências, dando início à reciclagem. Fonte: Elaborado pelos autores.

b) Água e papel foram colocados no liquidificador, na proporção de três partes de água para uma de papel e foram batidos por 10 segundos, até converter-se numa polpa;

c) A polpa foi despejada em uma bacia grande, maior que a moldura previamente construída;

d) A moldura vazada foi colocada sobre a moldura com tela e ambas foram mergulhadas verticalmente na bacia

e) Após alguns segundos, ambas foram suspensas, ainda na posição horizontal, bem devagar, de modo que a polpa ficasse depositada na tela (Figura 2) 


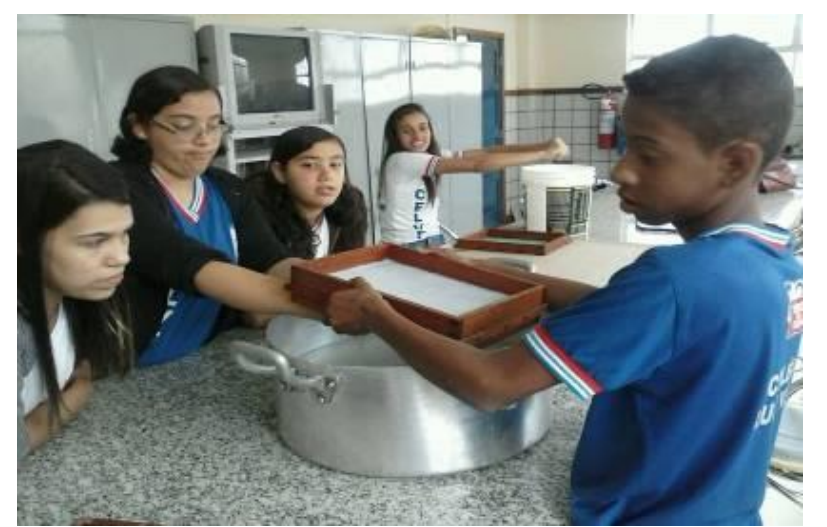

Figura 2: Alunos da Com-Vida elevando a moldura de madeira para depositar a polpa de papel. Fonte: Elaborado pelos autores.

f) Quando o excesso de água escorreu para dentro da bacia, e a polpa ficou retida na tela, a moldura vazada foi cuidadosamente retirada (Figura 3);

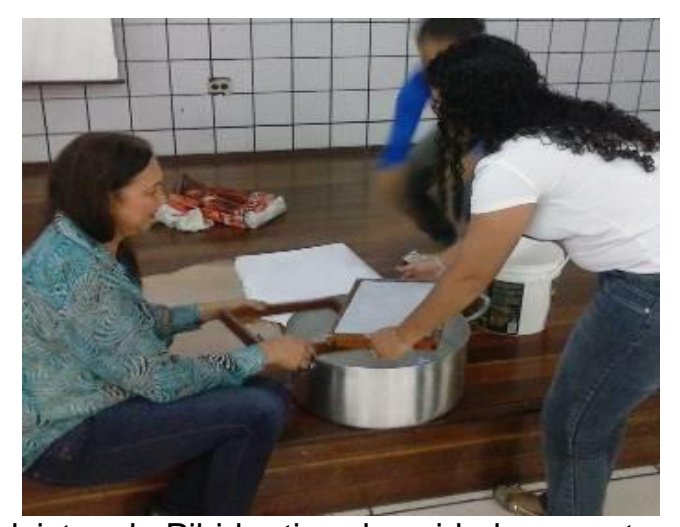

Figura 3: Bolsistas do Pibid retirando cuidadosamente a moldura vazada para colocar a folha sobre o papel madeira. Fonte: Elaborado pelos autores

g) A moldura com a polpa foi virada para baixo, sobre o papel madeira e o excesso de água foi retirado com uma esponja;

h) Em seguida, a moldura foi levantada, ficando a folha de papel, ainda úmida, sobre o papel madeira (Figura 4);

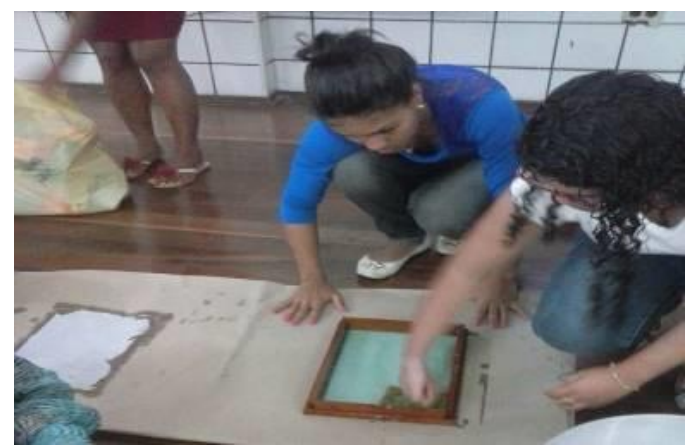

Figura 4: Bolsistas do Pibid colocando a folha úmida sobre o papel madeira.

Fonte: Elaborado pelos autores.

Revbea, São Paulo, V. 12, № 2: 114-126, 2017. 
i) Depois da secagem, a folha de papel foi retirada do papel madeira, e o papel reciclado estava pronto (Figura 5). Este mesmo procedimento foi repetido em um quarto encontro.

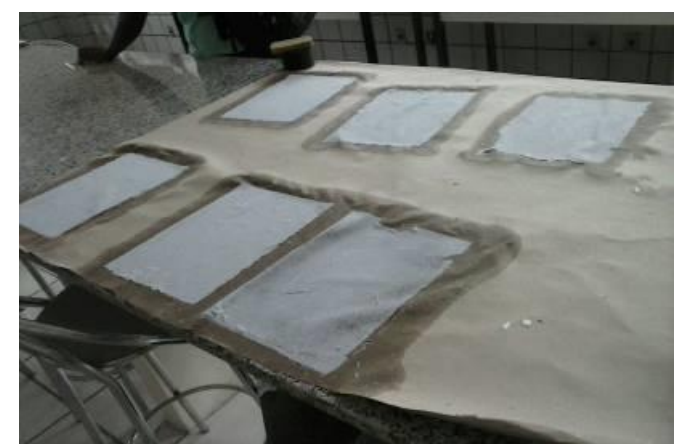

Figura 5: Folhas de papel reciclados, no processo de secagem.

Fonte: Elaborado pelos autores

Após as oficinas de reciclagem de papel, foi proposto um questionário de avaliação com quatro perguntas abertas no qual cinco alunos aceitaram responder.

\section{Resultados e Discussões}

O papel é um produto que é imprescindível no ambiente escolar, razão por que está sempre presente em quase tudo que se faz. A oficina de reciclagem de papel foi uma novidade para os alunos, e despertou o interesse e o envolvimento de todos. Além de ser uma prática fácil e de baixo custo, incentiva a participação individual e coletiva. Guimarães (2007) acredita que a Educação Ambiental deve proporcionar um ambiente educativo e participativo em que a aprendizagem se dê num processo de construção de conhecimentos vivenciais e experiências intencionais para que venham a intervir transformando a realidade, contribuindo para o enfrentamento da crise socioambiental do mundo moderno.

Conforme explica Trajber (2007), a Educação Ambiental propõe a formação de uma concepção crítica a respeito de descobertas conjuntas sobre a qualidade de vida e, ao mesmo tempo, sobre as maneiras de cuidar do pequeno planeta Terra. Dessa forma, não há como discordar de tal concepção. Isso ocorreu, por exemplo, com o posicionamento dos estudantes que responderam o questionário: todos destacaram a importância da EA para a melhoria da qualidade de vida e a incentivar o cuidado com o planeta. Embora de forma simples, os estudantes conseguiram captar a importância e os benefícios de práticas sustentáveis em prol da qualidade de vida quando identificaram em suas respostas ao questionário: 
Menos poluição (Participante 1)

Menos desmatamento e melhor qualidade do oxigênio (Participante 2)

[...] achei ótimo reciclar porque ajuda o planeta (Participante 2)

[...] poupa o meio ambiente de mais lixo (Participante 3 )

Trajber (2007) explica que a concepção de cuidar do planeta, apesar de ser, aparentemente, uma posição ingênua, propõe a formulação de novos valores na construção de uma sociedade sustentável. $E$ isso é de extrema importância para os educadores ambientais, ao ver que suas intervenções estão tendo resultados e que um número cada vez maior de estudantes ativos está tendo consciência de seus atos.

Outro ponto importante revelado pela atividade foi o destaque que o Participante 3 conferiu, nas suas respostas, à questão do lixo. É de conhecimento geral que todos dependem do consumo de alimentos, fonte de energia e disponibilidade de matéria-prima para a sobrevivência. No entanto, o homem precisa aprender que deve produzir e consumir de acordo com o que a Terra pode oferecer para assegurar a existência das condições favoráveis à vida (TRAJBER, 2007).

Infelizmente não é isso que vem acontecendo, pois ele consome muito além do que precisa para alimentar suas necessidades e desejos.

Outro aspecto a considerar é a utilização de materiais não recicláveis. A depender do tipo de papel, são necessários de três meses a vários anos para que este se decomponha. Embora nem todos os tipos sejam recicláveis, não se deve desconsiderar a importância da reciclagem para diminuir a quantidade de resíduos sólidos que são descartados de forma inadequada, poluindo por anos e podendo também entupir bueiros no período das enchentes.

Os participantes, nas suas respostas, disseram que os papéis reciclados deveriam ser usados em atividades escolares, na sala de aula, nos rascunhos, nas provas e também deram sugestões para melhorar e aumentar a produção de papel reciclado na escola como:

[...] deve-se reciclar de maneira mais contínua, pegamos somente o papel na secretaria, mas devíamos ter pegado na escola toda (Participante 1)

Conscientizar os outros alunos a reciclar (Participante 3)

Algumas turmas juntarem para fazer esse papel reciclado com um professor responsável (Participante 4)

De modo geral, os alunos manifestaram satisfação com o trabalho realizado. Além de terem gostado da oficina, eles sentem a necessidade de que se torne uma prática contínua e se estenda para as demais turmas do 
colégio, juntamente com outros professores. Para tanto, é necessário um maior interesse da comunidade escolar, o que de fato sentimos falta, visto que a Com-Vida é aberta tanto para a comunidade escolar quanto para seu entorno. A perspectiva da Educação Ambiental, mencionada por Guimarães (2007, p. 90), é "ampliar o ambiente educacional para além dos muros da escola, na comunidade local onde a escola está inserida, complementando a educação formal (escolar) com a não formal".

A respeito do que mudou na forma de agir e pensar depois da implantação da Com-Vida escolar e as oficinas realizadas em conjunto com o Pibid Interdisciplinar Educação Ambiental, os alunos disseram:

Que devemos ter consciência dos nossos atos para que não deprede 0 ambiente (Participante 3).

Passei a ver que a escola pode ser muito mais do que ela é, que trabalhos ambientais podem ser feitos no colégio para que melhore o desempenho dos alunos, em despesas do colégio (como a reciclagem do papel e nossa horta) e o melhoramento ambiental do colégio (Participante 5).

Verificou-se, assim, que as ações da oficina foram significativas para os alunos, pois evidenciaram interesse em repensar suas práticas, hábitos e ações sobre o ambiente e transpor suas ideias para as questões culturais, sociais, políticas e econômicas. Para Guimarães (2007), as práticas intencionais e coletivas através das intervenções educativas, que busca transformação da sociedade, devem se contextualizar também fora da escola, aplicando criticamente os conhecimentos curriculares, produzindo uma interpretação da realidade vivida, de maneira que esse processo de experiência promova a construção de novos conhecimentos alimentadores de novas práticas transformadoras.

Portanto, é necessário que os educadores, assegurem um ambiente em que os alunos possam ter experiências que reflitam a realidade (local e global) para que se tornem sujeitos críticos, conscientes dos conflitos de interesses econômicos, políticos e pessoais que assolam a nossa sociedade, e sejam capazes de interferir de forma positiva na realidade socioambiental.

\section{Considerações Finais}

O desenvolvimento da oficina de reciclagem do papel com os integrantes da Com-Vida pode ser considerado positivo, pois foi perceptível o envolvimento e interesse dos alunos, professores, escola e comunidade durante a realização da intervenção, a quantidade de papel que seria destinada ao lixo da escola, foi diminuindo, alcançando assim o objetivo proposto pela atividade. A reciclagem de papel é uma atividade fácil de ser realizada, de baixo custo e, além de tudo, estabelece relações interpessoais, pois, no envolvimento com a prática, os 
alunos vão ajudando uns aos outros (desenvolvendo a coletividade e respeitando as diferenças), além de consolidar a aprendizagem, podendo repensar e refletir sobre suas ações em relação ao meio ambiente.

A Educação Ambiental é uma possibilidade para a sustentabilidade, e a escola deve orientar as pessoas de forma decisiva, gerando ações em prol de um futuro melhor com qualidade de vida. Com isso, patenteia-se a importância do Pibid Interdisciplinar em Educação Ambiental na discussão e no desenvolvimento de ações com o objetivo de transformar a escola em um ambiente sustentável através do fazer pedagógico e da construção de conhecimentos e valores, formando cidadãos críticos, reflexivos e conscientes de suas ações na sociedade.

Porém, para que a escola se torne verdadeiramente sustentável, é necessário que haja continuidade dessas ações, para ressignificar o ensino da escola, com novas práticas, que consigam superar o consumismo e amenizar a crise civilizatória. No entanto, a Educação Ambiental não é um papel apenas da escola, mas é um conjunto de ações das diversas esferas sociais, econômicas, políticas, culturais, todos em busca de uma sociedade mais justa e sustentável.

\section{Agradecimentos}

A Coordenação de Aperfeiçoamento de Pessoal de Nível Superior (CAPES), pelo apoio financeiro as ex-bolsistas do Programa Institucional de Bolsas de Iniciação a Docência (Pibid) do Subprojeto Interdisciplinar em Educação Ambiental e autoras deste relato de experiência.

\section{Referências}

ALENCAR, M.M.M. Reciclagem de lixo numa escola pública do município de Salvador. Candombá - Revista Virtual, Salvador, v .1, n . 2, p. $96-113$, jul. - dez 2005.

BRASIL. Lei № 9.795 de 27 de abril de 1999. Dispõe sobre a Educação Ambiental, institui a Política Nacional de Educação Ambiental e dá outras providências. Diário Oficial do Distrito Federal, Brasília, 28 abr. 1999. Disponível em: <http://www.planalto.gov.br/ccivil 03/leis/19795.htm>. Acesso em: 16 nov. 2015.

BRASIL. Formando Com-Vida Comissão do Meio Ambiente e Qualidade de Vida na Escola : construindo Agenda 21 na Escola / Ministério da Educação, Ministério do Meio Ambiente. - Brasília: MEC, Coordenação Geral de Educação Ambiental, 2004.

FOLHA DA BRACELPA. São Paulo: BRACELPA, mai-jun/ 2009. Bimestral. Disponível em: <http://bracelpa.org.br/bra2/sites/default/files/folha/Folha Bracelpa-001.pdf $>$. Acesso em: 18 nov. 2015. 
FOLHA DA BRACELPA. São Paulo: BRACELPA, jan-abr/ 2010. Bimestral. Disponível em: <http://bracelpa.org.br/bra2/sites/default/files/folha/Folha Bracelpa-003.pdf>. Acesso em: 18 nov. 2015.

GUIMARÃES, M. Educação Ambiental: participação para além dos muros da escola. In: MELLO, S.S.; TRAJBER, R. (Coord.). Vamos cuidar do Brasil: conceitos e práticas em Educação Ambiental na escola. Brasília: UNESCO, p. 85-93, 2007.

JACOB, P. Educação e meio ambiente - transformando as práticas. Revista Brasileira de Educação Ambiental. Brasília, n. 0, p. 28-35, 2004.

LOUREIRO, C.F. Educar, participar e transformar em Educação Ambiental. Revista Brasileira de Educação Ambiental. Brasília, v.il., n. 0, p. 13-20, 2004.

LOUREIRO, C.F. Educação Ambiental Crítica: contribuições e desafios. In: MELLO, S.S.; TRAJBER, R. (Coord.). Vamos cuidar do Brasil: conceitos e práticas em Educação Ambiental na escola. Brasília: UNESCO, p. 65-71, 2007.

PINHEIRO, P.S.L. Um estudo sobre o antropocentrismo nos livros didáticos de ciências naturais para os anos iniciais do ensino fundamental. Dissertação de Mestrado (Pós-graduação em Educação Científica e Formação de Professores). Universidade Estadual do Sudoeste da Bahia. Jequié - Bahia, UESB, 2015.

SÃO PAULO (Estado) Secretaria do Meio Ambiente / Coordenadoria de Educação Ambiental. Guia Pedagógico do Lixo. São Paulo, 2011. 138. p.

SILVA, S.N; CARVALHO, G. Educação Ambiental no Programa Institucional de Bolsas de Iniciação à Docência: trabalho colaborativo entre universidade e escola pública no interior da Bahia. Saberes em perspectiva, Jequié, v.5, n.12, p. 7-26, maio/ago. 2015.

SILVA, S. N; EL-HANI, C. A abordagem do tema Ambiente e a formação do cidadão socioambientalmente responsável. Revista Brasileira de Pesquisa em Educação em Ciências, v. 14, n. 2, p. 225-234, 2014.

TRAJBER, R. Cidadania e consumo sustentável: nossas escolhas em ações conjuntas. In: MELLO, S.S.; TRAJBER, R. (Coord.). Vamos cuidar do Brasil: conceitos e práticas em Educação Ambiental na escola. Brasília: UNESCO, p. 143-150, 2007. 